\title{
Influence of the amount of deformation on the change in the porosity of sinters subjected to free cold upsetting
}

\author{
Mariusz Rosiak $^{1, *}$, and Jerzy Napiórkowski ${ }^{2}$ \\ ${ }^{1}$ Opole University of Technology, Faculty of Mechanical Engineering, Department of Manufacturing \\ Engineering and Production Automation, ul. S. Mikołajczyka 5, 45-271 Opole, Poland \\ ${ }^{2}$ University of Warmia and Mazury in Olsztyn, Faculty of Technical Sciences, Exploitation and \\ Diagnostics Vehicles and Machines. St. M. Oczapowskiego 11, 10-079 Olsztyn, Poland
}

\begin{abstract}
The article contains a description of the technology production of cylindrical samples sintered of powder by using input material conditions of a trial deformation. The results of changes in porosity before and after the deformation are analyzed. Analysis of changes in the internal structure of the sinters were based on maps prepared porosity distribution for the states of deformation, carried out in conditions of freedom compression cold. Currently we are looking for effective methods of processing sintered towards obtaining the highest possible density of the homogeneous character the distribution volume. In the present study we analyzed the impact of the classical way of deformation sintered to changes in the internal structure due to the evolution of porosity. The study used an original approach to the assessment of porosity in the local areas, was conducted quantitative metallographic share porosity, based on the results prepared model the spatial distribution maps porosity.
\end{abstract}

\section{Introduction}

Unlike solid materials which are similar in terms of chemical composition, sinters are characterised by the presence of voids and discontinuities in the internal structure that are called porosity. Porosity is an important element of the internal structure of sinters, because its amount and nature of distribution in the material volume has a significant influence on final properties of the product. The amount of porosity and its diversification are influenced by a number of factors, such as e.g. properties of input powder, type of slip additives, mixing conditions of the prepared input material, pressing conditions and sintering conditions. Sinters prepared in this way under conditions typical to the powder metallurgy technology reach a minimum value of porosity within the range of $10-25 \%$. Sintered products operating under heavy loading conditions require high strength properties that are possible to be obtained at a low evenly distributed porosity. In case of solid materials, studies on the effective deformation using plastic characteristics of materials to a greater extend, have been conducted for many years. In their papers [1-3], Bochniak and Korbel

\footnotetext{
"Corresponding author: m.rosiak@po.opole.pl
} 
indicate that the influence of the strain path on the efficiency of material forming is significant. Other authors, e.g. Grosman and Pawlicki also presented in their papers new possibilities of effective deformation of solid materials under complex loading states [4-9]. Rosiak [10] used a deformation method under complex loading conditions used by other researchers for the deformation of solid materials under volumetric strains of sinters. Deformation conditions that he used were the same as in the test of free compression with simultaneous reverse torsion. The aim of the paper was to find a new method for intensive and even compaction of sinters. He came to a conclusion that deformation of sinters under conditions of free compression with simultaneous reverse torsion favours an intensive and even compaction of the material volume and obtaining low and poorly diversified porosities.

This paper presents the influence of simple loading conditions created as in the test of free compression due to the possibility of compacting and obtaining low and evenly distributed porosity at the level allowing for possible heat or thermochemical treatment carried out under conditions as for solid materials.

\section{Methodology and materials used for testing}

\subsection{Characteristics of powder for preparing samples}

The input material for testing was collected on the basis of the following criteria: material susceptibility to cold forming, susceptibility to heat and thermochemical treatment, possibilities of using materials in industrial technological processes, availability in the market and economic relations.

Table 1. Chemical composition of the powder used to fabricate the sinters [11].

\begin{tabular}{|c|c|c|c|}
\hline \multirow{4}{*}{$\begin{array}{c}\text { Chemical } \\
\text { element }\end{array}$} & \multicolumn{3}{|c|}{ Type of powder } \\
\cline { 2 - 4 } & \multicolumn{3}{|c|}{ NC 100.24 } \\
\cline { 2 - 4 } & \multicolumn{3}{|c|}{ Content of chemical element } \\
\cline { 2 - 4 } & min. & max. & real \\
\hline $\mathrm{H}_{2}$ loss & - & - & 0.21 \\
\hline $\mathrm{C}$ & - & - & $<0.01$ \\
\hline $\mathrm{Ni}$ & - & - & - \\
\hline $\mathrm{Cu}$ & - & - & - \\
\hline $\mathrm{Mo}$ & - & - & - \\
\hline $\mathrm{Fe}$ & - & - & The rest \\
\hline
\end{tabular}

Sinters are made of NC 100.24 powder manufactured in the technology of the reduction of iron oxides contained in the ore with solid substances [11]. Chemical compositions of the powder used for the preparation of sinters are presented in table 1, the granularity of the powder is shown in table 2 .

NC 100.24 powder is one of the most widely used powders in the powder metallurgy. It is characterised by a spongy structure that allows for a favourable stress distribution and high resistance of products, which makes it possible to manufacture moulded parts with low and high degrees of compaction (fig.1). Good compactibility (compressibility) of NC 100.24 powder ensures that it can be widely used in the manufacture of parts in the powder 
metallurgy. NC 100.24 powder was prepared by adding $0.7 \%$ of the slip additive - zinc stereate and mixing in the Y-type 2-channel mixer by Apex for 1 hour.

Table 2.Grain size of the powder used to fabricate the sinters [11].

\begin{tabular}{|c|c|}
\hline \multirow{2}{*}{$\begin{array}{c}\text { Grain size w } \\
\mu \mathrm{m}\end{array}$} & Type of powder \\
\cline { 2 - 2 } & NC 100.24 \\
\cline { 2 - 2 } & Fraction $\%$ \\
\hline+212 & 0.0 \\
\hline $150-212$ & 1.0 \\
\hline $106-150$ & \\
\hline $75-106$ & 81.0 \\
\hline $45-75$ & \\
\hline-45 & $18 ., 0$ \\
\hline
\end{tabular}

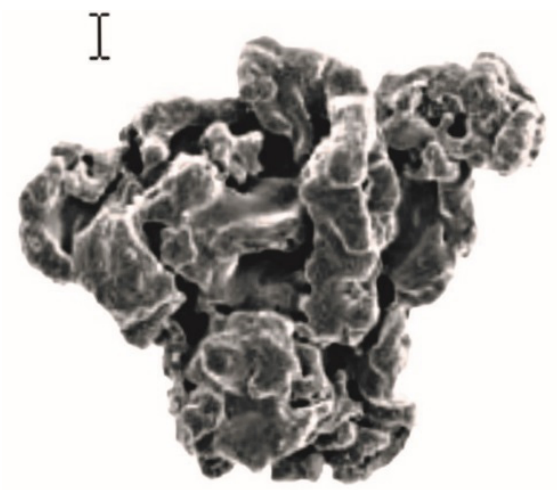

Fig.1. Image grains of iron powder NC 100.24 from Höganäs [11].

\subsection{Conditions of preparing sintered samples}

In order to assess the influence of the effects of plastic deformation of sinters on the porosity distribution in the finished product, the author decided to prepare sintered samples with the density $\rho_{\mathrm{w}}=0,80$ and having an axial-symmetric shape in the form of rolls (height $\mathrm{h}=20 \mathrm{~mm}$ and diameter $\mathrm{d}=20 \mathrm{~mm}$-the shape of samples that was chosen is often used in tests conducted for this type of materials and described in literature [12-14]). Theoretical and relative densities of prepared sinters are presented in table 3 and 4.

Sintered samples were prepared, using standard conditions for conducting processes of powder metallurgy in the following order:

- preparation of weighted amounts of powder;

- compression of weighted amounts of powder in a locked die with the diameter $\mathrm{d}_{\mathrm{w}}=20$ $\mathrm{mm}$, using distance to obtain height equal to $\mathrm{h}=20 \mathrm{~mm}$, (carried out with the use of the WPM-type strength machine with a maximum pressure force of $300 \mathrm{kN}$ );

- sintering of fittings at the temperature of $1100{ }^{\circ} \mathrm{C}$ under an atmosphere of endogas for 0.5 hour (endogas atmosphere was obtained as a result of the reaction of the air-propane mixture heated to $900^{\circ} \mathrm{C}$ with hydrocarbon in the presence of a nickel catalyst; air/propane ratio was 10:1; composition of the atmosphere: $31 \% \mathrm{H}_{2}, 23 \% \mathrm{CO}+\mathrm{CO}_{2}, 46 \% \mathrm{~N}_{2}$ ), sintering was carried out using the SAFED belt furnace;

- annealing was carried out under an atmosphere of hydrogen at the temperature of $900{ }^{\circ} \mathrm{C}$, sintering was carried out using the SAFED belt furnace; 
- calibration process was carried out using a low die. Obtained diameters of samples were within the range from $20.05 \mathrm{~mm}$ to $20.07 \mathrm{~mm}$.

Table 3.Theoretical density sintered (without pores) [11].

\begin{tabular}{|c|c|c|c|c|c|}
\hline \multirow{3}{*}{$\begin{array}{c}\text { Type of powder } \\
\text { Ty }\end{array}$} & \multicolumn{3}{|c|}{2} & 3 \\
\cline { 2 - 5 } & $\mathrm{Cu}$ & $\mathrm{Ni}$ & $\mathrm{Mo}$ & $\mathrm{Fe}$ & $\begin{array}{c}\text { Theoretical density } \\
\text { sintered (without pores) } \\
{\left[\mathrm{g} / \mathrm{cm}^{3}\right]}\end{array}$ \\
\hline NC 100.24 & - & - & - & The rest & 7.800 \\
\hline
\end{tabular}

Table 4.Density produced sintered (own work).

\begin{tabular}{|l|c|}
\hline \multirow{3}{*}{ Type of powder } & The relative density of sintered $\rho_{\mathrm{w}}$ \\
\cline { 2 - 2 } & 0.80 \\
\cline { 2 - 2 } & Density of sinters $\rho\left[\mathrm{g} / \mathrm{cm}^{3}\right]$ \\
\hline NC 100.24 & 6.24 \\
\hline
\end{tabular}

\subsection{Conditions of plastic deformation of sinters}

Samples obtained after compaction and sintering of metallic powders consist of a metallic matrix and discontinuities that are geometrically differentiated and randomly distributed in the volume of the sinter. The essential feature that distinguishes the sintered metallic material (porous material) from solid metallic materials is the fact that during the deformation process, there are changes in the volume in addition to changes in the form. It is possible to form a porous material under any stress state even at the hydrostatic pressure. Porous materials are characterised by a slightly lower formability limit in comparison with solid materials. Unlike solid materials, sintered performs have the following features (that are often considered to be disadvantages): internal porosity, oxide layers in the surface layer, impurities and segregation of additives added to the basic mixture. These disadvantages are possible places of cracks that precede the damage to the material and reduce at the same time its susceptibility to forming. During plastic forming of sinters, it is required to generate such a stress state that will allow for a plastic flow of the matrix and will not cause local tensile stresses contributing to the increase in the local porosity or even fracture in the microregions of forging. Sinters under large plastic deformations are characterised by the minimum porosity that is evenly distributed in the volume and high strength properties.

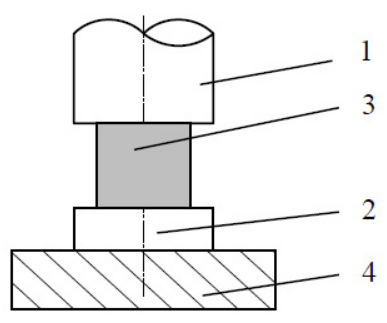

Initial position



Deformation phase

Fig. 2. Deformations phases of compressed samples in dies; 1 - upper punch, 2 - lower punch, 3 sample, 4 - pad. 
In order to assess the evolution of the porosity in the volume of forging under free upsetting conditions (Fig. 2), the author decided to use the variants of forming of sinters by means of deformations allowing for obtaining the required diameter in the plane of the maximum spinning of the barrel up to the assumed values: $\mathrm{I}-\mathrm{d}_{1 \mathrm{~b}}=22 \mathrm{~mm}, \mathrm{II}-\mathrm{d}_{2 \mathrm{~b}}=23 \mathrm{~mm}$, III $-\mathrm{d}_{3 \mathrm{~b}}=24 \mathrm{~mm}, \mathrm{IV}-\mathrm{d}_{4 \mathrm{~b}}=25 \mathrm{~mm}$ (Fig. 2). Preforms were formed using the hydraulic press of type LB-500. At the time of carrying out tests upsetting recorded: force $F[N]$, the displacement $\Delta \mathrm{h}[\mathrm{mm}]$, the time $\tau[\mathrm{s}]$. The maximum compressive forces which was reached during the implementation of the trial amounted to about 0.2 [MN]. On the basis of the recorded data during the compression tests were developed to strengthen the function of the material (1).

$$
\sigma_{0.80}=555.34 *(0.1015+\varphi)^{0.5953}
$$

\section{Results and discussion}

\subsection{Results of porosity after the implemented deformation variations}

Table 5 shows the results of the porosity and density of sinters during the deformation phase (based on the geometrical criterion); they were deformed in a way ensuring that the required diameter in the plane of the maximum diameter of the barrel corresponds to the assumed values: I $-\mathrm{d}_{1 \mathrm{~b}}=22 \mathrm{~mm}$, II $-\mathrm{d}_{2 \mathrm{~b}}=23 \mathrm{~mm}$, III $-\mathrm{d}_{3 \mathrm{~b}}=24 \mathrm{~mm}, \mathrm{IV}-\mathrm{d}_{4 \mathrm{~b}}=25 \mathrm{~mm}$. The value of the $\rho$ and $\rho \mathrm{w}$ density was also determined using the hydrostatic weighing method [6] in relation to the whole density of sinters (Fig. 3), where the change in the density depended on the deformation phase, i.e. the size of the deformation $\varphi$. The change in the value of the average porosity in the volume of the sinter in relation to the value of the sinter $\theta=\mathrm{f}(\varphi)$ is shown in Fig. 4 .

The porosity value of the sinter before plastic deformation, the value of the deformation in process, and the friction force in the contact plane between the tool and the deforming material etc., which all contribute to the fact that the deformation process is uneven in local areas, have a considerable impact on the value and porosity distribution of the sinter deformed in the free compression test. In order to obtain small porosities, the sinter has to be intensively compacted.

Table 5. Change in the average porosity of the volume sinters after the free compression deformation (change in the density $\rho$, and the relative density $\rho_{w}$ in relation to the entire volume of the sinter).

\begin{tabular}{|c|c|c|c|c|}
\hline \multicolumn{2}{|c|}{ Type in the sinter powder } & \multicolumn{2}{|c|}{ NC 100.24} & \multirow{2}{*}{$\begin{array}{c}\text { The average volume } \\
\text { porosity }\end{array}$} \\
\hline \multirow{2}{*}{\multicolumn{2}{|c|}{ Before deformation }} & $\rho\left[\mathrm{g} / \mathrm{cm}^{3}\right]$ & $\rho_{\mathrm{w}}$ & \\
\hline & & 6.24 & 0.80 & 20 \\
\hline \multicolumn{5}{|c|}{ Density and porosity after the phase of deformation } \\
\hline I & $\begin{array}{c}\mathrm{d}_{1 \mathrm{~b}}=22 \\
\mathrm{~mm}\end{array}$ & 6.6621 & 0.85 & 15 \\
\hline II & $\begin{array}{c}\mathrm{d}_{2 \mathrm{~b}}=23 \\
\mathrm{~mm}\end{array}$ & 6.8757 & 0.88 & 12 \\
\hline III & $\begin{array}{c}\mathrm{d}_{3 \mathrm{~b}}=24 \\
\mathrm{~mm}\end{array}$ & 7.0417 & 0.90 & 10 \\
\hline IV & $\begin{array}{c}\mathrm{d}_{4 \mathrm{~b}}=25 \\
\mathrm{~mm}\end{array}$ & 7.1797 & 0.92 & 8 \\
\hline
\end{tabular}




$$
\begin{array}{ll} 
& \rho_{w}=\frac{\rho_{s}}{\rho} \\
\rho_{w} & \text { - relative density, } \\
\rho_{s} & \text { - density sintered }\left[\mathrm{g} / \mathrm{cm}^{3}\right], \\
\rho & \text { - sintered density without pores }\left[\mathrm{g} / \mathrm{cm}^{3}\right],
\end{array}
$$

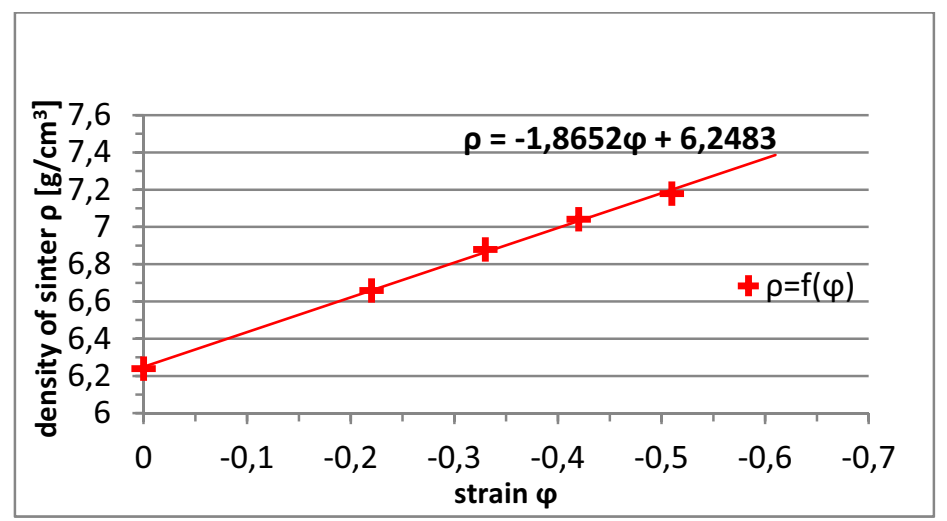

Fig.3. Variation of the average density $\rho=\mathrm{f}(\varphi)$ deformed in a free compression test.

Big deformations in the free cold compression test of sinters favour the increase in the density of the deformed material and the reduction of its porosity. If the 3-4\% porosity of sinters is obtained, the heat and thermochemical treatment can be applied under the same conditions as for solid materials, which greatly facilitates the manufacture of sintered products. It is possible to deform sinters with big deformations in the range of values that do not cause the limit value $\varphi_{\text {gr }}$ to be exceeded in local areas. The loss of the structural integrity and, consequently, the damage to the material may be caused if the limit value is exceeded. The increase in the average value of density is proportional to the value of the deformation under the conditions of free compression of sinters (Fig. 3).

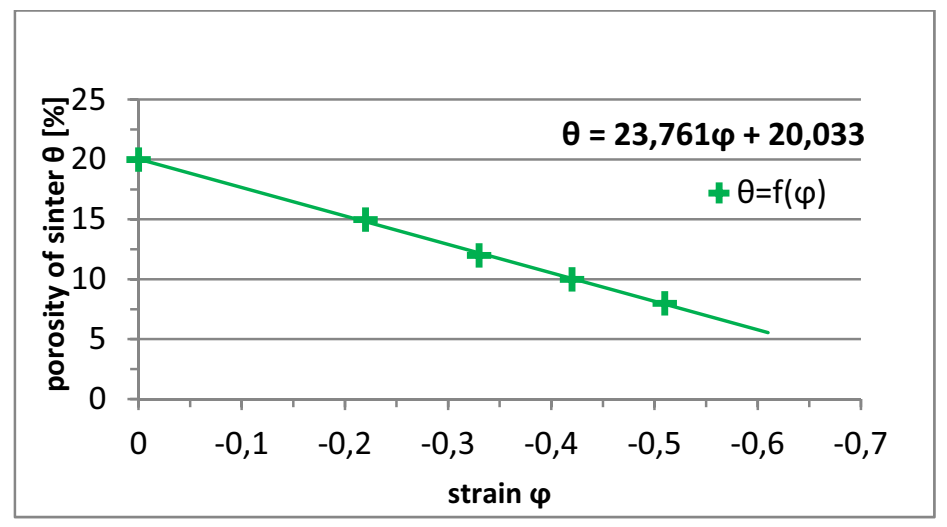

Fig.4. Variation of the average porosity $\theta=f(\varphi)$ deformed in a free compression test.

The average porosity value decreases proportionally to the achieved deformation as the deformation in process proceeds (Fig.4). The uneven deformation process in local areas affects the size and porosity distribution in the volume of the sinter, which is reflected in different properties of the material in particular cross-sections. 


\subsection{Results of porosity distribution after the completed deformation variants}

On the longitudinal section, in the axis of the cylinders, metallographic microsections were made and porosity was assessed in local areas.

Table 6. Distribution of porosity $\Theta$ in the sintered before deformation.

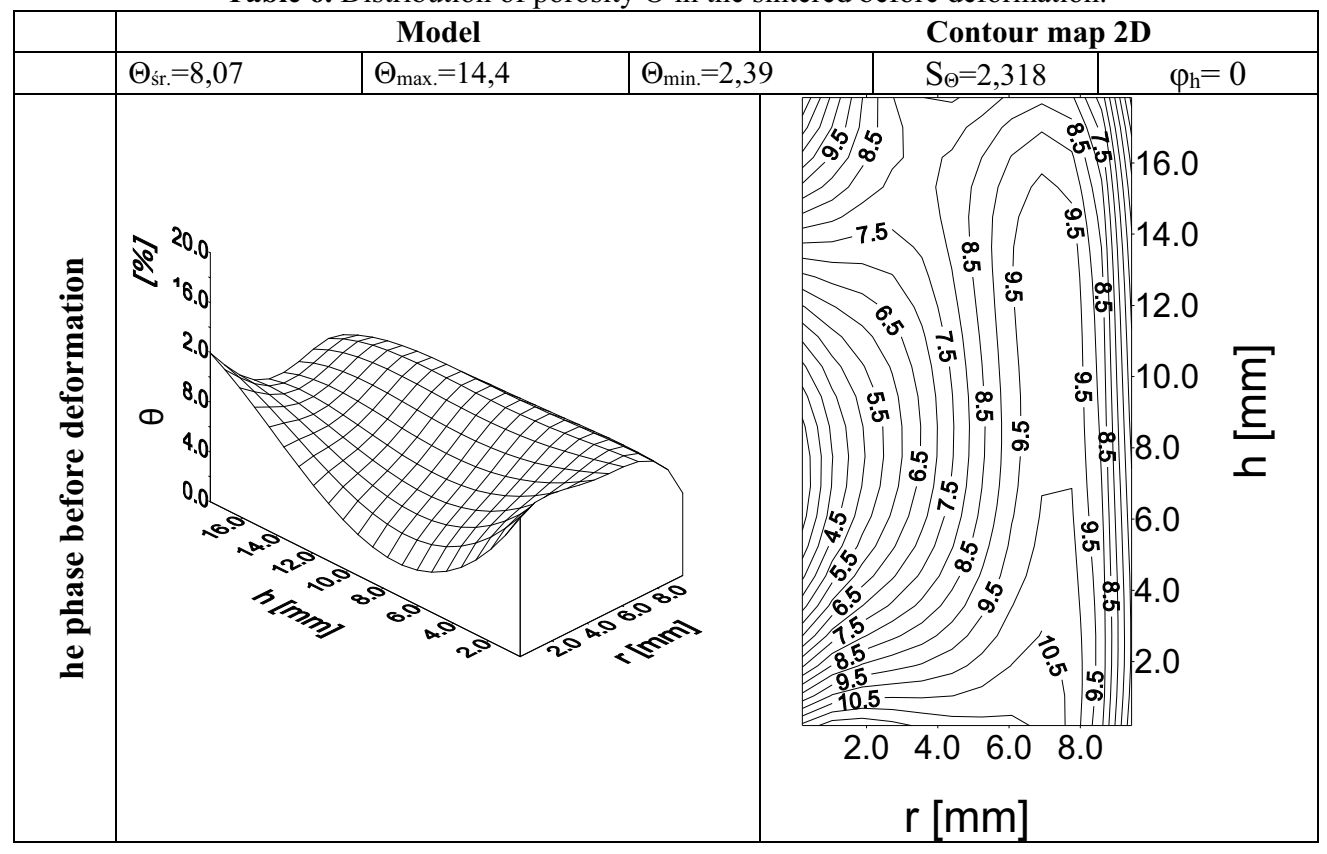

The height of the sample was divided into 20 rows. In each of them 12 equidistant elementary areas were specified for the analysis. Using the capabilities of quantitative image analysis, the features of the objects in the form of pore sections were analysed. Maps of porosity were prepared on the basis of the obtained measurement results. Maps showing porosity distributions with isolines and plastic maps were made on the basis of a thirddegree polynomial function determined by the interpolation method. Examples of porosity distribution before and after selected deformation stages are presented in tables 6-8.

The analyses carried out after the forming tests of sinters made it possible to determine the progress of compaction of these materials, expressed by the porosity distribution function. The porosity features expressed by parameters, such as the density, shape and size of pores, were also subject to significant changes during the deformation. The analysis of the porosity distribution in the zones of the emerging barrel indicates that the compaction progresses considerably less intensively and even after the fourth deformation stage porosity is high and will significantly affect the diversification of the distribution of material properties in local areas, also determining the nature of the course of phenomena taking place in the material during heat treatment or thermochemical treatment.

Porosity in sinters before deformation (table 6) carried out in the conditions of classical operations of powder metallurgy is highly varied in the entire volume of the sample. The lowest porosity is present in the axis, in the central part of the cylinder. In the zones at the base and the surface of the cylinder porosity has a considerable higher share in the internal structure of the sinter. Sinters prepared in such a way, deformed by means of free upsetting with low deformations (table 7) maintain a similarly uneven distribution of porosity, with a slightly lowers average value of the share of pores. 
Table 7. Distribution of porosity $\Theta$ in the sintered after the first phase of deformation $\left(\mathrm{d}_{1 \mathrm{~b}}=22 \mathrm{~mm}\right)$.

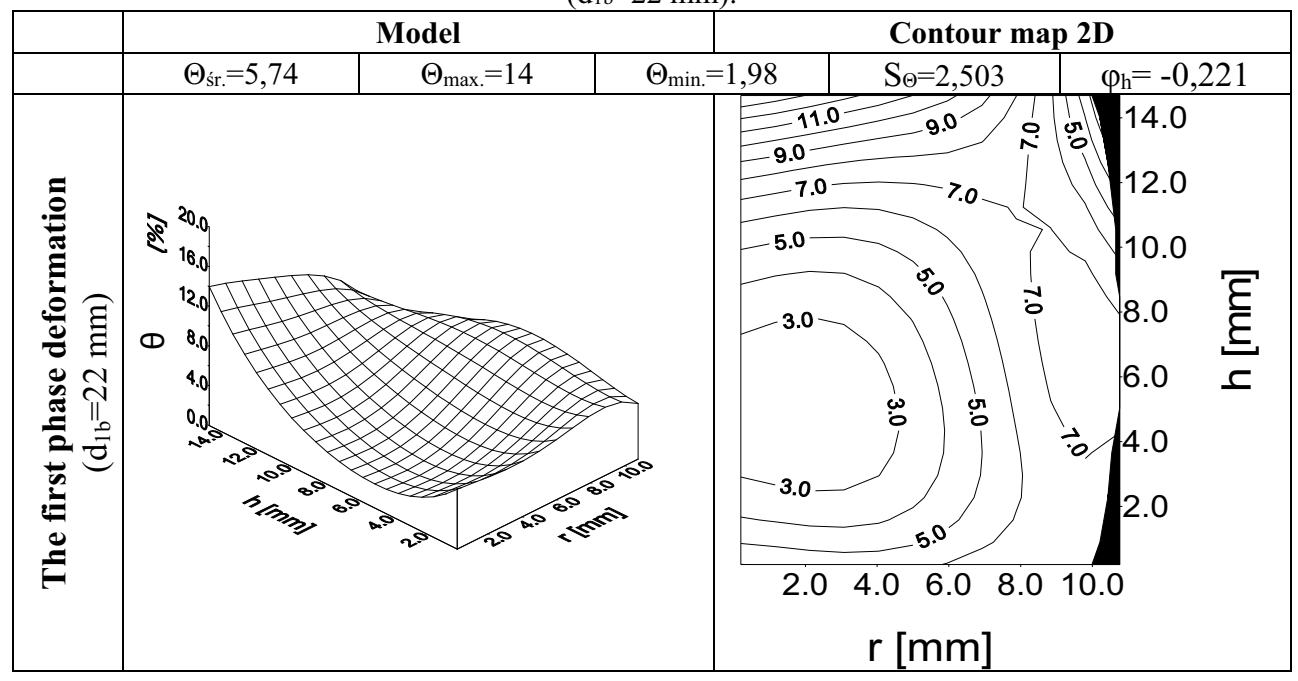

Table 8. Distribution of porosity $\Theta$ in the sintered after the fourth phase of deformation $\left(\mathrm{d}_{4 \mathrm{~b}}=25 \mathrm{~mm}\right)$.

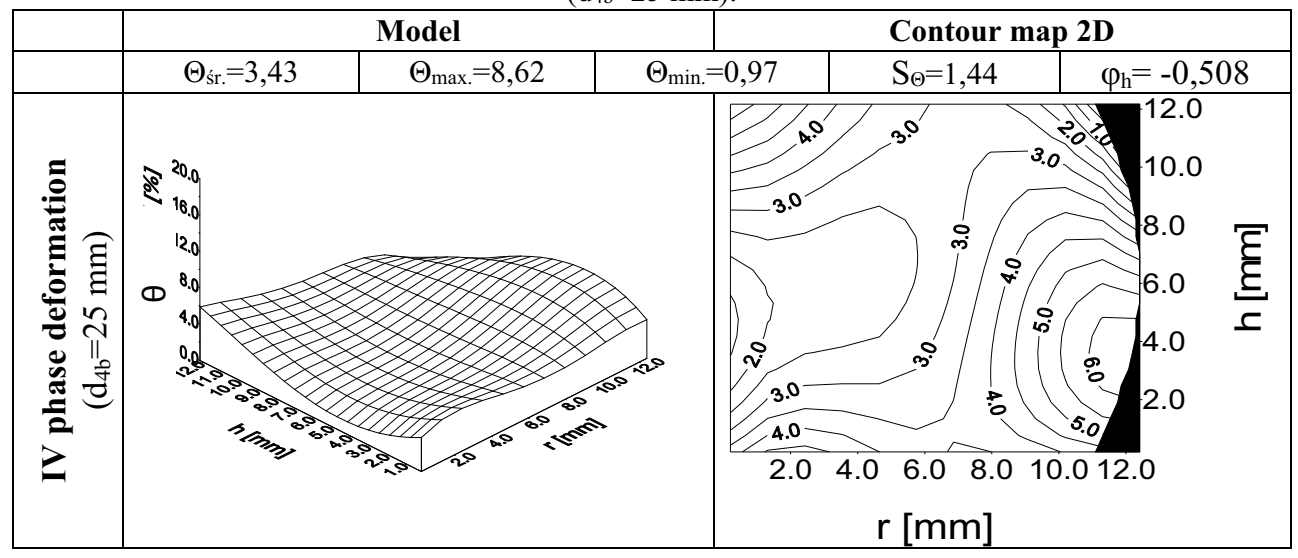

The application of high deformations $\phi \approx-0,5$ (table 8), not exceeding $\varphi_{\text {gr }}$, makes it possible to significantly reduce the values of the average porosity and obtain low diversification of its distribution. Such values and distribution of porosity allow heat treatment and thermochemical treatment under the same conditions as for solid materials which are similar in terms of chemical composition.

\section{Conclusions}

The special character of porous materials requires a careful analysis of the impact of the factors that cause changes in the internal structure in the scope of the metallic matrix and changes in porosity features. During the sintering of sintered porous materials, as in the case of solid materials, the progress of deformation in local areas is not homogenous. The heterogeneity of the progress of deformation in local areas affects more or less intensive compaction of the material of the sinter, causing the reduction or even disappearance of pores. The reduction of porosity after plastic deformation is the reason for the reduction of 
the volume of the deformed sinter. Therefore, in contrast to solid materials, the principle of maintaining the same volume does not apply during forming of sinters.

The changes in the internal structure of the sintered material for the discussed variants of the deformation progress depend on the condition of the material before the deformation and the value of the upset as well as the nature of the deformation progress in local areas. The value and distribution of porosity in sinters before deformation determines the nature of the progress of porosity changes in the subsequent stages of deformation. The material in the central zone (in local areas of the volume) is subject to high compaction and reduction of porosity already after the deformation. After the fourth stage, the compaction becomes almost homogeneous and the material reaches almost uniform porosity. For such a distribution of porosity, the relevant literature indicates the possibility of accepting a porous material (with low porosity) for heat treatment under the conditions recommended for solid materials.

The studies permit analysis of the evolution of the distribution of porosity depending on the amount of deformation under compression freely. Most literature porosity evaluation is determined by an average value of the initial state before the deformation and the final state after deformation. Statement of the porosity distribution to the various states of deformation under compression increases substantially knowledge of changes in the internal structure of the sintered plastically deformed cold.

The examination of the assessment of the deformation progress of sinters performed under the conditions of a free upsetting test made it possible to formulate the following conclusions:

- It is possible to deform porous metallic sinters under the conditions of free compression, which results in a possibly high compaction of the material.

- However, low average value of porosity obtained after free upsetting is highly varied in local areas, which results in diverse final properties in the sinter volume. This is not a good method when you want to get big and uniform density. Low and uniform porosity is obtained by other methods, e. g. deforming sinters closed die or deforming sinters in complex load conditions - compression freely while oscillating torsion.

- Free upsetting of sintered materials does not make it possible to obtain a uniform compaction in the volume and therefore a uniform distribution of porosity.

- Forming of porous materials includes the diversification of the deformation in local areas and its impact on structural changes, as is the case of solid materials where the density is constant, and the change in the volume resulting from the change in the density.

- The size and distribution of pores depend on the evolution of the local stress and strain states.

- The research improves the knowledge of the possibility of analyzing changes in porosity in the sintered compression freely for the various stages of deformation. Most literature porosity of the sinter is analyzed for the state before and after complete deformation.

\section{References}

1. W. Bochniak, A. Korbel, Journal of Materials Processing Technology, 134, 120-134 (2003)

2. A. Korbel, W. Bochniak, Philosophical Magazine, 93, 15, 1883-1913 (2013)

3. W. Bochniak, A. Korbel, P. Ostachowski, A. Paliborek, International Journal of Materials Research, 104, 10, 974-979 (2013)

4. F. Grosman, J. Pawlicki, Hutnik-Wiadomości Hutnicze R., 72/5, 280-284 (2005)

5. F. Grosman, J. Pawlicki, Advanced Technology of Plasticity, 1, 1219-1224 (2002) 
6. J. Pawlicki, Hutnik - Wiadomości Hutnicze 8, 438-440, (2010)

7. J. Pawlicki, Rudy I Metale Nieżelazne 11, 550-558 (2015)

8. F. Grosman, J. Pawlicki, Hutnik - Wiadomości Hutnicze, 5, 231-235 (2008)

9. J. Pawlicki, K. Hyc, Rudy I Metale Nieżelazne 11, 679-683 (2013)

10. M. Rosiak,. Archives of Metallurgy and Materials 4, 58, 1197-1205 (2013)

11. Hoganas AB, Metal Powders, www.hoganas.com

12. M. Rosiak, Grosman F. Zeszyty Naukowe Politechniki Opolskiej, 290, seria Mechanika z. 76, 305-309 (2003)

13. M. Rosiak, F. Grosman, Zeszyty Naukowe Politechniki Opolskiej 288, seria Mechanika z. 75, s. 211-218 (2002)

14. J. Łukowski, Zeszyty Naukowe Politechniki Śląskiej, seria Hutnictwo, 44 (1992) 